\title{
Successful application of laparoscopic and endoscopic cooperative surgery (LECS) for a lateral-spreading mucosal gastric cancer
}

\author{
Souya Nunobe $\cdot$ Naoki Hiki $\cdot$ Takuji Gotoda $\cdot$ Takahisa Murao $\cdot$ Ken Haruma \\ Hideo Matsumoto • Toshihiro Hirai - Shinya Tanimura • Takeshi Sano • \\ Toshiharu Yamaguchi
}

Received: 26 October 2011 / Accepted: 26 January 2012/Published online: 17 February 2012

(c) The International Gastric Cancer Association and The Japanese Gastric Cancer Association 2012

\begin{abstract}
In the current era of endoscopic submucosal dissection (ESD) for early gastric cancer, which carries a negligible risk of lymph node metastasis, local resection of the stomach remains an option for these lesions. This is particularly so for a large intramucosal lesion or a lesion with a strong ulcer scar, for which ESD becomes a difficult option. Here, we describe a case of lateral-spreading intramucosal gastric cancer of 6-cm diameter located at the fornix of the stomach, which was successfully treated by laparoscopic and endoscopic cooperative surgery (LECS) because of the expected risk of complications during ESD. In the LECS procedure, the resection margin was appropriately determined by the endoscopic evaluation in detail and by the ESD technique. If early gastric cancer fits the criteria for endoscopic resection but would present difficulty if performing ESD, this is a good indication for the LECS procedure.
\end{abstract}

S. Nunobe $\cdot$ N. Hiki $(\bowtie) \cdot S$. Tanimura $\cdot$ T. Sano

T. Yamaguchi

Department of Gastroenterological Surgery, Cancer Institute

Ariake Hospital, 3-8-31, Ariake, Koto-ku,

Tokyo 135-8550, Japan

e-mail: naoki.hiki@jfcr.or.jp

T. Gotoda

Department of Gastroenterology, National Center for Global

Health and Medicine, Tokyo, Japan

T. Murao $\cdot$ K. Haruma

Department of Gastroenterology, Kawasaki Medical School,

Okayama, Japan

H. Matsumoto $\cdot$ T. Hirai

Department of Gastroenterological Surgery, Kawasaki Medical

School, Okayama, Japan
Keywords Early gastric cancer - Laparoscopic local resection - Laparoscopic and endoscopic cooperative surgery (LECS)

\section{Introduction}

Endoscopic submucosal dissection (ESD) is accepted as a less invasive local resection for early gastric cancer (EGC) that carries a negligible risk of lymph node metastasis $[1,2]$. Based on the estimated risk of lymph node metastasis in EGC obtained from a large number of surgical cases [3, 4], the criteria for ESD in EGC has been expanded to include larger lesions of intramucosal cancer $(>21 \mathrm{~mm}$ in diameter) or ulcerated lesions. However, the ESD procedure is still complicated, and these expanded indications for ESD have been accompanied by a higher incidence of bleeding and perforation, particularly with large EGC lesions, as well as longer operation times [5-7].

Before the development of ESD, some patients with EGC underwent local resection of the stomach using a lesion-lifting technique [8-12]. However, the indication for this approach rapidly decreased because of problems with determining the exact tumor dissection line while maintaining safe cutting margins, and thereafter ESD became the main treatment of EGC [9].

With the aim of appropriate resection of the gastric wall, we developed the laparoscopic and endoscopic cooperative surgery (LECS) technique and applied it to dissecting out submucosal tumors of the stomach [13]. In LECS, the location of the tumor is first confirmed endoscopically, followed by submucosal dissection using intraluminal endoscopy to determine an appropriate resection line. Then, the seromuscular layer is dissected laparoscopically, and the incision line is closed using a laparoscopic stapling device. 
Here, we have introduced the LECS technique for gastric cancer and describe a case of lateral-spreading intramucosal gastric cancer with characteristics within the extended criteria for ESD, which was treated by LECS because of the expected risk of complications during ESD treatment.

\section{Case report}

A 70-year-old female was referred by her general practitioner to the hospital for the treatment of EGC. Endoscopic examination revealed a lateral-spreading intramucosal tumor, $6 \mathrm{~cm}$ in diameter, located at the fornix of the stomach, which was diagnosed as a histologically tubular adenocarcinoma. Computed tomography and ultrasonography showed no lymph node or distant metastasis. The proposed treatment was laparoscopic local resection using LECS because of the risks of perforation and bleeding with ESD accompanied by a lengthy operation.

\section{LECS for a lateral-spreading gastric cancer}

The LECS procedure was performed as described previously [13]. In the present case, we were particularly careful to prevent contact between the mucosal tumor and the visceral tissues. Thus, the tumor was dissected laparoscopically while keeping the resected specimen inverted into the intragastric space and not exposed to the nearby viscera.

\section{Confirmation of tumor location and dissection of peripheral vessels for preparation}

After setup for laparoscopic surgery, the tumor location was confirmed by intraluminal endoscopy (H260; Olympus, Tokyo, Japan). The stomach wall was maneuvered from the mucosal side using biopsy forceps to aid tumor visualization. The 6-cm-diameter tumor was located at the greater curvature of the fornix, and the estimated depth of invasion was intramucosal.

Blood vessels in the excision area around the tumor were prepared using an ultrasonically activated device (Harmonic Ace; Ethicon Endo-Surgery, Cincinnati, OH, USA). In the present case, the short gastric artery was divided and the fornix of the stomach was mobilized to provide a better working space.

\section{ESD around the tumor and laparoscopic seromuscular dissection}

First, the periphery of the tumor was marked to the tumor edge with a $1-\mathrm{cm}$ margin using a forced $20-\mathrm{W}$ coagulation

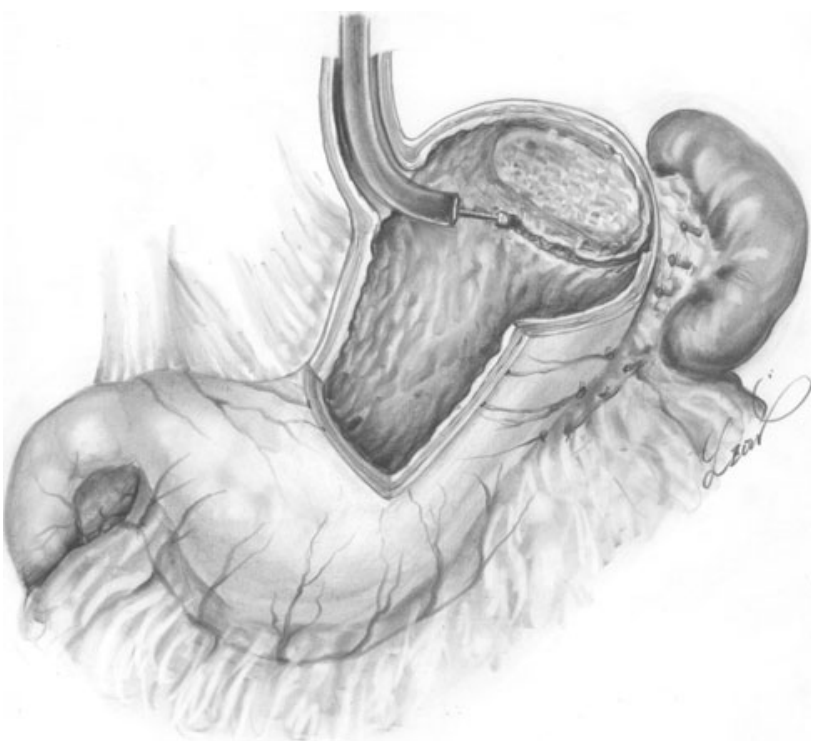

Fig. 1 After a small initial incision has been made using a standard needle knife, the tip of the insulation-tipped diathermic electrosurgical (IT-2) knife is inserted into the submucosal layer. Then, the marked area is cut circumferentially using the IT- 2 in the 80 -W PulseCut slow mode

current (ESG-100; Olympus Co.). Then, the marked area was cut circumferentially using the IT knife in the $80-\mathrm{W}$ Pulse-Cut slow mode (Fig. 1). Finally, the opening of the submucosa was pushed toward the serosa using the IT knife [IT-2 (KD-611L; Olympus Co.)].

The tip of the needle knife was visible on the laparoscopic image beyond the seromuscular layer and was used to perforate the seromuscular layer in the 100-W Endo-Cut mode. The tip of the ultrasonically activated device was inserted into the perforation and seromuscular dissection started. The seromuscular layer was dissected along the incision line using the ultrasonically activated device. During dissection, the appropriate dissection line was easily identified because of the endoscopic submucosal resection around the tumor and its confirmation both laparoscopically and endoscopically. To prevent contact between the tumor and the visceral tissue, the tumor was inverted to face the intragastric cavity using the traction of the stitch at the edge of the resected specimen, and the resection line of the stomach was pulled up like a bowl by several stitches (Fig. 2). Each of the stitches pulling together the edges of the stomach incision was pulled out of the abdominal cavity using the Endo Close ${ }^{\mathrm{TM}}$ site closure device (Covidien, Tokyo, Japan). The needle of the Endo Close $^{\mathrm{TM}}$ device punctures directly from the outside of the abdominal wall. After the tumor had been resected into the gastric cavity and collected via the per-oral route, the edge of the incision line was closed temporarily using handsewn sutures. The incision line was then properly closed using a laparoscopic stapling device (Endo-GIA II; 


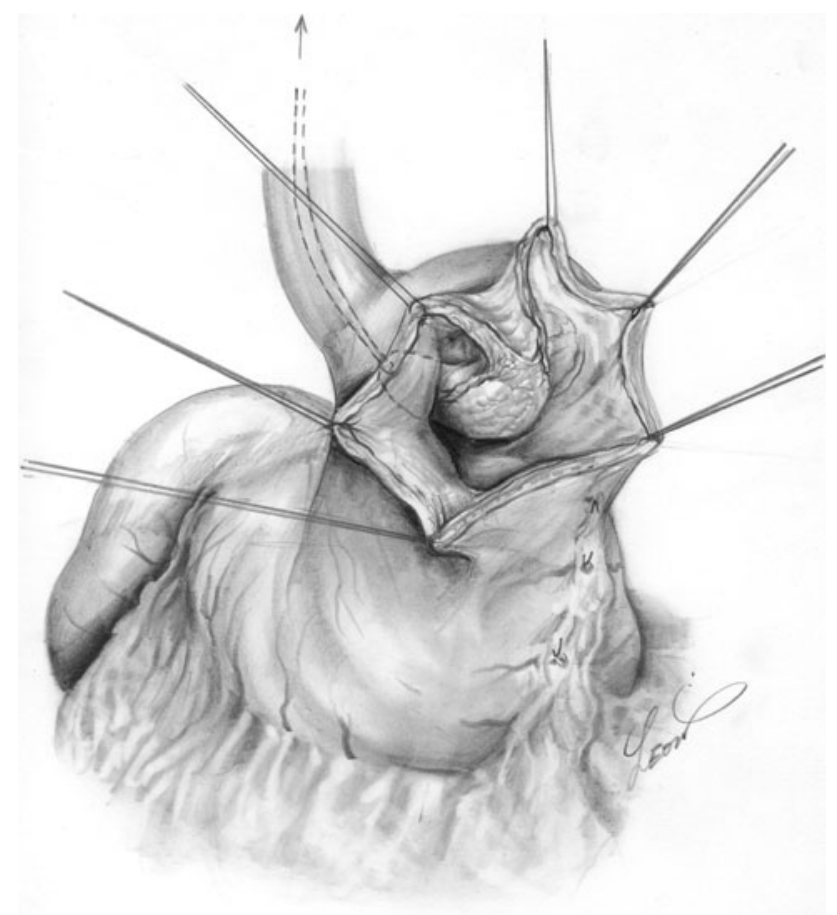

Fig. 2 The seromuscular layer is dissected along the incision line using the ultrasonically activated device (HARMONIC ACE; Ethiocon Endo-Surgery), which prevents major bleeding from the muscular layer. To prevent contact between the tumor and the visceral tissue, the tumor is inverted to face the intragastric cavity using the traction of the stitch at the edge of the resected specimen, and the resection line of the stomach is pulled up like a bowl by several stitches

Covidien, Tokyo, Japan), with particular care paid to the direction and margin of the suture line (Fig. 3).

An air leak test was performed by endoscopic insufflation, and the absence of bleeding was confirmed using both endoscopy and laparoscopy. No drainage tube was inserted.

The operation time was $152 \mathrm{~min}$, and estimated blood loss was $0 \mathrm{ml}$ during the operation. The postoperative course was almost uneventful.

Pathological examination confirmed that the tumor was intramucosal, measuring $60 \times 47 \mathrm{~mm}$ in diameter, and showing no lymphatic or venous invasion. The resected specimen was $80 \times 63 \mathrm{~mm}$ in diameter with negative lateral and vertical margins.

\section{Discussion}

In the present case, LECS was successfully applied to a large spreading mucosal cancer in the stomach that would have been difficult to treat with ESD because of the high incidence of complications and the long surgical time required for ESD. It is essential during LECS procedures for epithelial neoplasms that tumor cells are not seeded into

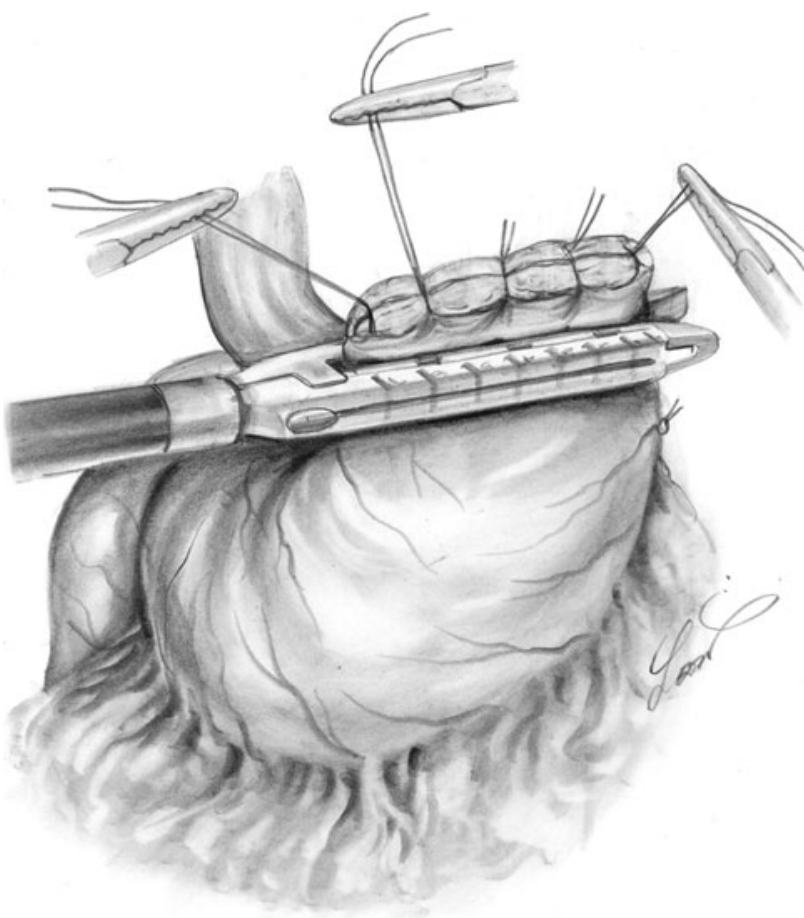

Fig. 3 The incision line is then properly closed using a laparoscopic stapling device (Endo-GIA II; Tyco Healthcare, Tokyo, Japan), with particular care paid to the direction and margin of the suture line

the peritoneal cavity. In order to prevent contact of the tumor with visceral tissue, the tumor was turned toward the intra-gastric cavity by traction on the stitches at the edge of the resected specimen, and the resection line of the stomach was pulled up like a bowl by several stitches. Only gastric perforation during ESD for gastric cancer has been reported not to lead to peritoneal dissemination, even with long-term observation [14]. Therefore, the LECS procedure in the present case was safe from the oncological viewpoint.

To prevent the risk of cancer cells seeding during open gastrectomy, non-exposure gastric wall full-thickness resection techniques such as "CLEAN-NET" or "NEWS" have been developed $[15,16]$. CLEAN-NET is a technique for the full-thickness resection of the stomach wall using only laparoscopy and then using endoscopy to confirm the dissected line, whereas NEWS is a technique that uses endoscopy to assist with the laparoscopic approach. However, the mucosal layer shifts significantly from the seromuscle layer during surgery, so that the muscle layer and sero-muscle layer may be incorrectly dissected using CLEAN-NET and NEWS. This can result in the inappropriate resection of the stomach wall.

During local resectioning of the stomach for mucosal gastric cancer surgery, it can be difficult to determine the exact dissection line in order to provide an adequate safety margin from the tumor edge when approaching from the 
Table 1 Comparison of ESD and LECS for wide intramucosal gastric cancer

\begin{tabular}{lll}
\hline & ESD & LECS \\
\hline Anesthesia & Local & General \\
Place & Endoscopic room & Operation room \\
Manpower & One & Four \\
$\begin{array}{l}\text { Technical difficulties } \\
\text { Operation time }\end{array}$ & Difficult & Not so difficult \\
predicted (h) & $3-4$ & $2-3$ \\
$\begin{array}{l}\text { Morbidities predicted } \\
\text { Preferable location }\end{array}$ & Frequent & Lower third of stomach \\
$\begin{array}{c}\text { Deformation of } \\
\text { stomach }\end{array}$ & $\begin{array}{l}\text { To some extent due to } \\
\text { ulcerative change }\end{array}$ & To some extent \\
\hline
\end{tabular}

ESD endoscopic submucosal dissection, LECS laparoscopic and endoscopic cooperative surgery

exterior of the stomach. Laparoscopic local resection of the stomach using the lesion-lifting technique has been applied to gastric cancer with a negligible risk of lymph node metastasis [8-11]. Ohgami et al. reported a relatively high rate of local recurrence (3.3\%: $2 / 61$ cases) after laparoscopic local resection of the stomach using the lesion-lifting method compared with the results of ESD for EGC [9, 17]. Therefore, the number of indications for local resection of the stomach was rapidly decreased, and ESD became the main treatment for EGC. In the LECS procedure, the resection margin would be appropriately determined by endoscopic evaluation in detail and by the ESD technique. The LECS procedure combines the ESD technique and laparoscopic gastric wall resection, which prevents excessive resection and deformation of the stomach after surgery.

The standard treatment for EGC is gastrectomy with lymph node dissection according to the Japanese gastric cancer treatment guidelines [18]. Recently, the indication criteria in Japan for endoscopic resection of EGC have been expanded to include large intramucosal cancer lesions that are more than $21 \mathrm{~mm}$ in diameter and lesions with ulcer scars. This has occurred since the emergence of ESD as an experimental treatment, which has enabled the endoscopic resection of difficult lesions including large lesions or those with ulcer scars $[3,4,19,20]$. Large lesions within the extended criteria are usually treated by ESD, not by surgery, in Japanese clinical settings. A phase II clinical trial is underway in Japan (JCOG 0607) to estimate the feasibility of ESD for EGC within the extended criteria [21]. Theoretically, it should be possible to dissect any lesion by the ESD technique, regardless of its size or the presence of ulcerative changes. However, ESD is a complicated technique and requires a high level of skill from endoscopists. This is especially true for larger lesions because of the more difficult extension of the wall, and the collection of fluid, including blood and/or gastric juices, can hinder ESD and result in a low rate of complete removal of the EGC in one piece [6,7]. Increased incidences of bleeding and perforation are associated with the expanded indication of ESD for large EGC lesions as well as increased surgery time for ESD [5]. The incidence of decreased hemoglobin levels and perforation associated with ESD for large lesions of more than $31 \mathrm{~mm}$ was 12 and $8 \%$, respectively. In addition, the mean surgical time for ESD for large lesions was $134 \mathrm{~min}$, with some cases taking more than $4 \mathrm{~h}$ [5].

The use of the LECS procedure is indicated for EGCs that would be difficult to treat with ESD, including large lesions of more than $30-\mathrm{mm}$ diameter located at the greater curvature of the gastric body or fornix, or for lesions with strong ulcerative changes. LECS is safe and feasible, with a reasonable surgical time [13]. Table 1 shows a comparison of the benefits and limitations of ESD and LECS for wide intramucosal gastric cancer and includes peri-treatment factors. Although considerable time and effort are required during LECS, it is safe and feasible for any lesion. If the sentinel lymph node concept is established in the surgical treatment for gastric cancer, then the indications for LECS for EGC could be expaned in the future, which could result in increasingly successful gastric cancer treatment.

Acknowledgments The authors would like to thank Mr. Leon Sakuma for the artwork in the figures.

\section{References}

1. Rembacken BJ, Gotoda T, Fujii T, Axon T. Endoscopic mucosal resection. Endoscopy. 2001;33:709-18.

2. Soetikno RM, Gotoda T, Nakanishi Y, Soehendra N. Endoscopic mucosal resection. Gastrointest Endosc. 2003;57:567-79.

3. Eguchi T, Gotoda T, Oda I, Hamanaka H, Hasuike N, Saito D. Is endoscopic one-piece mucosal resection essential for early gastric cancer? Dig Endosc. 2003;15:113-6.

4. Gotoda T, Yanagisawa A, Sasako M, Ono H, Nakanishi Y, Shimoda $\mathrm{T}$, et al. Incidence of lymph node metastasis from early gastric cancer: estimation with a large number of cases at two large centers. Gastric Cancer. 2000;3:219-25.

5. Oda I, Gotoda T, Hamanaka H, Eguchi T, Saito Y, Matsuda T, et al. Endoscopic submucosal dissection for early gastric cancer: technical feasibility, operation time and complications from a large consecutive series. Dig Endosc. 2005;17:54-8.

6. Gotoda T, Oda I, Tamakawa K, Ueda H, Kobayashi T, Kakizoe T. Prospective clinical trial of magnetic-anchor-guided endoscopic submucosal dissection for large early gastric cancer (with videos). Gastrointest Endosc. 2009;69:10-5.

7. Rosch T, Sarbia M, Schumacher B, Deinert K, Frimberger Etoermer $\mathrm{T}$, et al. Attempted endoscopic en bloc resection of 
mucosal and submucosal tumors using insulated-tip knives: a pilot series (including videos). Endoscopy. 2004;36:788-801.

8. Ludwig K, Klautke G, Bernhard J, Weiner R. Minimally invasive and local treatment for mucosal early gastric cancer. Surg Endosc. 2005;19:1362-6.

9. Ohgami M, Otani Y, Kumai K, Kubota T, Kim YI, Kitajima M. Curative laparoscopic surgery for early gastric cancer: five years experience. World J Surg. 1999;23:187-92.

10. Hiki Y, Sakuramoto S, Katada N, Shimano H. Kombiniertes laparoskopisch-endoskopisches Vorgehen beim Magenkarzinom. Chirurg. 2000;71:1193-201.

11. Kobayashi T, Kazui T, Kimura T. Surgical local resection for early gastric cancer. Surg Laparosc Endosc Percutan. 2003;13: 299-304.

12. Seto Y, Yamaguchi H, Shimoyama S, Shimizu N, Aoki F, Kaminishi M. Results of local resection with regional lymphadenectomy for early gastric cancer. Am J Surg. 2001;182:498-501.

13. Hiki N, Yamamoto Y, Fukunaga T, Yamaguchi T, Nunobe S, Tokunaga $\mathrm{M}$, et al. Laparoscopic and endoscopic cooperative surgery for gastrointestinal stromal tumor dissection. Surg Endosc. 2008;22:1729-35.

14. Ikehara H, Gotoda T, Ono H, Oda I, Saito D. Gastric perforation during endoscopic resection for gastric carcinoma and the risk of peritoneal dissemination. Br J Surg. 2007;94:992-5.
15. Inoue H, Ikeda H, Hosoya T, Yoshida A, Onimaru M, Suzuki M, et al. Endoscopic mucosal resection, endoscopic submucosal dissection, and beyond: full-layer resection for gastric cancer with nonexposure technique (CLEAN-NET). Surg Oncol Clin N Am. 2012;21:129-40.

16. Goto O, Mitsui T, Fujishiro M, Wada I, Shimizu N, Seto Y, et al. New method of endoscopic full-thickness resection: a pilot study of non-exposed endoscopic wall-inversion surgery in an ex vivo porcine model. Gastric Cancer. 2011;14:183-7.

17. Oda I, Saito D, Tada M, Iishi H, Tanabe S, Oyama T, et al. A multicenter retrospective study of endoscopic resection for early gastric cancer. Gastric Cancer. 2006;9:262-70.

18. Japanese Gastric Cancer Association. Japanese gastric cancer treatment guidelines 2010 (ver. 3). Gastric Cancer. 2011;14:113-23.

19. Gotoda T, Kondo H, Ono H, Saito Y, Yamaguchi H, Saito D, et al. A new endoscopic mucosal resection procedure using an insulation-tipped electrosurgical knife for rectal flat lesions. Gastrointest Endosc. 1999;50:560-3.

20. Ono H, Kondo H, Gotoda T, Shirao K, Yamaguchi H, Saito D, et al. Endoscopic mucosal resection for treatment of early gastric cancer. Gut. 2001;48:225-9.

21. Kurokawa Y, Hasuike N, Ono H, Boku N, Fukuda H. Gastrointestinal Oncology Study Group of Japan Clinical Oncology Group. Jpn J Clin Oncol. 2009;39:464-6. 